\title{
Characterization of tyramine $\beta$-hydroxylase, an enzyme upregulated by stress in Periplaneta americana
}

\author{
Amélie Châtel ${ }^{1,2, *}$, Laurence Murillo ${ }^{1,3}$, Céline Michelle Bourdin ${ }^{1}$, Sophie Quinchard', \\ Damien Picard ${ }^{4}$ and Christian Legros ${ }^{1, *}$ \\ 'Laboratoire Récepteurs et Canaux loniques Membranaires (RCIM) UPRES EA 2647/USC INRA 1330, SFR QUASAV, \\ Université d'Angers, 2 boulevard Lavoisier, F-49045 Angers Cedex, France \\ ${ }^{2}$ Université Nantes, Mer Molécules Santé (MMS), EA 2160, Faculté de Pharmacie, 1 rue Gaston Veil, BP53508, 44035 \\ Nantes Cedex 1, France \\ ${ }^{3}$ Laboratoire LIttoral ENvironnement et Sociétés (LIENSs), UMR 7266 CNRS-Université de La Rochelle, Institut du \\ Littoral et de l'Environnement, 2 rue Olympe de Gouges, 17000 La Rochelle, France (present address) \\ ${ }^{4}$ GECCO Groupe Ecologie et Conservation des Vertébrés, Faculté des Sciences, Université d'Angers, 2 bd Lavoisier, \\ 49045 Angers, France \\ *(A Châtel and C Legros contributed equally to this work) \\ (A Châtel is now at Université Catholique de l'Ouest, Institut de Biologie et Ecologie Appliquée, 44 rue Rabelais, \\ 49008 Angers Cedex 1, France) \\ (C Legros is now at Laboratoire de Biologie Neurovasculaire et Mitochondriale Intégrée, UMR 6214 CNRS, INSERM \\ 1083, UFR de Sciences Médicales, Université d'Angers, 1 rue Haute de Reculée, F-49045 Angers cedex, France)
}

Correspondence should be addressed to A Châtel Email amelie.chatel@uco.fr

\begin{abstract}
Octopamine (OA) is an important neuroactive substance that modulates several physiological functions and behaviors of various invertebrate species. This biogenic monoamine, structurally related to noradrenaline, acts as a neurotransmitter, a neuromodulator, or a neurohormone in insects. The tyramine $\beta$-hydroxylase $(\mathrm{TBH})$ catalyzes the last step in OA biosynthesis and thus plays a key role in the regulation of synthesis and secretion of OA in neurons. The aim of this study was to characterize TBH in the cockroach Periplaneta americana and to get a better understanding of its regulation under stress conditions in this insect. First of all, five full-length CDNAs encoding TBH isoforms were cloned from the nerve cord of the physiological model $P$. americana. PaTBH transcripts were found mainly expressed in nervous tissues and in octopaminergic dorsal unpaired median neurons.

In addition, a new ELISA assay was developed so as to allow determination of both OA level and TBH activity in stressed cockroaches. Mechanical stressful stimulation led to a significant increase in TBH activity after 1 and $24 \mathrm{~h}$, with a higher induction after $1 \mathrm{~h}$ than after $24 \mathrm{~h}$. Thus, TBH could be considered as a promising biomarker of stress in insects rather than OA.
\end{abstract}

\section{Key Words}

- tyramine $\beta$-hydroxylase

- Periplaneta americana

- CDNA cloning

- ELISA test

- octopamine

- nervous tissue

- stress

\section{Introduction}

Arthropoda biogenic phenolamine octopamine (OA) and its precursor tyramine are believed to be the functional counterparts of the vertebrate adrenergic mediators.
OA controls various peripheral functions including heart and visceral muscle contractions, pheromone biosynthesis and perception, flight muscle activity, and release of
Journal of Molecular Endocrinology (2013) 50, 91-102 
neurohormones (Roeder 1999, 2005). In insects, OA is found at high concentrations in the peripheral nervous system, CNS, and other insect tissue (Axelrod \& Saavedra 1977, Evans 1985). In the CNS, OA is essential for regulation of motivation, desensitization of sensory inputs, and initiation and maintenance of learning and memory (Farooqui 2007). OA may also mediate the excitation-induced hypertrehalosemia, which is the 'EXIT' response observed in the cockroach Periplaneta americana (Matthews \& Downer 1974, Downer 1979).

Biosynthesis of $\mathrm{OA}$ is processed in two steps: a decarboxylation of tyrosine by tyrosine decarboxylase to form tyramine, which is subsequently hydroxylated by tyramine $\beta$-hydroxylase (TBH) to produce OA (Livingstone \& Tempel 1983). Although this later step appears to be very important in the modulation of $\mathrm{OA}$ amounts in the tissues, little information is available about TBH activity in insects. In response to stressful stimuli, the metabolic systems are activated by releasing $\mathrm{OA}$ and other several mediators, including juvenile hormone, dopamine, and ecdysteroids (Orchard \& Loughton 1981, Davenport \& Evans 1984, Woodring et al. 1988, Hirashima \& Eto 1993, Hirashima et al. 2000, Rauschenbach et al. 2000). In more recent studies, it has been shown that OA levels are modified in various insect species in response to stressors such as temperature changes (Davenport \& Evans 1984, Hirashima et al. 2000, Chentsova et al. 2002), mechanical and chemical stress (Davenport \& Evans 1984, Harris et al. 1996), and high population density (Kozanek et al. 1986).

Only few studies have focused on the relationship between expression/activity of the TBH and OA synthesis in insects. Biochemical property analysis of a partially purified TBH from the thoracic nervous system of the lobster Homarus americanus had demonstrated that TBH is necessary for the hydroxylation of tyramine to produce $\mathrm{OA}$ and that this reaction is dependent on $\mathrm{pH}$, ascorbic acid, copper, and catalase (Wallace 1976, Lehman et al. $2000 a, b)$. During Manduca sexta development, TBH activity is increased in the brain and in the ganglia, in correlation with an increase in OA levels during metamorphosis reflecting that OA levels are developmentally regulated (Lehman et al. 2000a,b). Lehman et al. (2006) have demonstrated that elevated OA levels in forager honey bee brain were correlated with an increase in the expression of gene encoding $\mathrm{TBH}$, indicating a link between transcriptional activity, OA levels in the brain, and the regulation of social behavior in honey bees.

To gain further insight into OA regulation in the cockroach $P$. americana, we have cloned full-length cDNA encoding TBH-related enzyme expressed in nervous tissue. In addition, we built up a novel ELISA assay for OA measurement to explore both OA state and TBH activity of stressed cockroaches.

\section{Materials and methods}

\section{Organisms}

The cockroaches $P$. americana were maintained in the laboratory under standard conditions $\left(29^{\circ} \mathrm{C}\right.$, photoperiod of $12 \mathrm{~h}$ light: $12 \mathrm{~h}$ darkness, food and water ad libitum). Intestine, ganglia, mushroom accessory glands, muscles (extracted from the coxa of the legs), head, and the ventral nerve cord (thoracic and abdominal ganglia, together with the connectives) were dissected from adult male cockroaches.

\section{CDNA cloning and RT-PCR assays}

Total RNA was isolated from various tissues using the TRIzol Reagent (Invitrogen), and RT was performed using the SuperScript III First-Strand Synthesis SuperMix kit (Invitrogen). PCR experiments were performed with GoTaq polymerase (Promega) and the amplicons of expected size were purified using NucleoSpin Extract II (Macherey-Nagel, Düren, Germany) and cloned into pCR4-TOPO (Invitrogen) for sequencing (Millegen, Labège, France).

For cloning a TBH-related partial cDNA, a degenerate primer set (Table 1) was designed from TBH of Drosophila melanogaster amino acid sequence (GenBank ID: Z70316) and used in a PCR experiment with cDNA from nerve cord. The partial cDNA sequences encoding TBH-related proteins were extended toward $3^{\prime}$ and $5^{\prime}$ directions by RACE methods (GeneRacer kit, Invitrogen) using genespecific primers (GSP1, GSP2, GSP3, and GSP4; Table 1). To isolate full-length $P a T B H$ cDNAs $(1.7 \mathrm{~kb})$, a primer pair encompassing the open reading frame of $P a T B H$ was designed: a forward primer (GSP5) and a reverse primer (GSP3; Supplementary Table S1). For amplifying fulllength cDNAs encoding PaTBH, a high-fidelity ADN thermostable polymerase was used according to the manufacturer (KOD HiFi DNA Polymerase; Novagen, Darmstadt, Germany). Each clone was sequenced twice on both strands using universal sense and reverse primers.

Tissue expression pattern of PaTBH transcripts was performed by RT-PCR experiments using the sense primer GSP1 and the reverse primer GSP3 (Table 1) as described previously (Moignot et al. 2009). For multiplex single-cell RT-PCR, isolated dorsal unpaired median (DUM) neurons

Published by Bioscientifica Ltd. 
Table 1 Sequences of the oligonucleotides used in PCR and their corresponding region

\section{Primer names}

(A) Degenerated primers used to amplify partial TBH CDNAs

TH-DS

TH-DR

(B) Specific primers used in RACE and to amplify the full-length ORF

$5^{\prime}-$ GSP1

$5^{\prime}-\mathrm{GSP} 2$

$3^{\prime}-$ GSP3

$3^{\prime}-\mathrm{GSP} 4$

$5^{\prime}$-GSP5

\section{Nucleotide sequence $\left(5^{\prime}-3^{\prime}\right)$}

\section{CCNWSNCARGARACNACNTAYTGGTG} GDATRTARTTNACRCACATYTCRTC

CAAGCATCACGTGGTGCAATAC
GCCAACGGAAGGCATACTCA
GTACATATCTAGTTATGACTATATGG
TGAGTATGCCTTCCGTTGGC
GGAGTAGAAAAGTCTTCGCGAGAC

${ }^{a}$ Designation of oligonucleotide mixtures: $R=A+G ; Y=C+T ; S=G+C ; H=A+C+T ; N=A+G+C+T ; W=A+T$. $S$, sens; $R$, reverse.

were prepared as already described (Lavialle-Defaix et al. 2010). The cytoplasm of a single neuron was harvested via a patch-pipette mounted on a micromanipulator. Total RNA was reverse transcribed into first-strand cDNA as described earlier and used as template for two round multiplex nested PCR products, using specific gene primers (Table 2). PCR products obtained were purified for direct sequencing.

\section{Stress paradigm}

A total of 48 cockroaches ( 24 males and 24 females) were used throughout the study. Insects were randomly assigned to one of the three different experimental groups (16 cockroaches per group: eight males and eight females). In mechanical stress groups, shaking was applied for a period of 1 or $24 \mathrm{~h}$ using an orbital shaker. During the stress procedure, insects were placed in glass cages with dimensions $200 \times 10 \times 10 \mathrm{~cm}$
(16 cockroaches in each cage) at room temperature and were completely deprived of food and water. Control group (unstressed cockroaches) was isolated for $1 \mathrm{~h}$.

\section{Preparation of homogenate}

All steps were performed under dim light. Cockroaches were killed by decapitation. Thoracic and abdominal ganglia were immediately removed and rinsed in ice-cold normal saline solution $\left(150 \mathrm{mM} \mathrm{NaCl}, 3 \mathrm{mM} \mathrm{KCl}, 3 \mathrm{mM} \mathrm{CaCl}_{2}\right.$, $20 \mathrm{mM} \mathrm{MgCl}_{2}$, and $10 \mathrm{mM} \mathrm{N}$-Tris(hydroxymethyl)methyl2-aminoethanesulfonic acid, $\mathrm{pH}$ 6.9) (Christensen et al. 1992). Tissues were frozen in liquid nitrogen and stored at $-80^{\circ} \mathrm{C}$. After weighting, the tissues were homogenized in saline solution ( $500 \mathrm{ml}$ per $100 \mathrm{mg}$ tissue) using a pestle. The homogenate was centrifuged $\left(10 \mathrm{~min}, 10000 \mathrm{~g}, 4^{\circ} \mathrm{C}\right)$. Supernatant containing enzyme extract was collected, aliquoted, and kept frozen $\left(-80^{\circ} \mathrm{C}\right)$ until use.

Table 2 Sequences of the oligonucleotides used in single-cell multiplex PCR and their corresponding region

\begin{tabular}{|c|c|c|c|}
\hline Gene (partial) & Nucleotide sequence $\left(5^{\prime}-3^{\prime}\right)$ & Product length (bp) & GenBank ID \\
\hline Actin & $\begin{array}{l}\text { CTGACCCTTAAATACCCCATTG } \\
\text { CACAATTTCTCGTTCGGCGTG } \\
\text { CACGGTATCGTGACCAACTG } \\
\text { GTAAAGCTGTAACCACGCTCAG }\end{array}$ & $\begin{array}{l}435^{a} \\
386 \text { (nested) }\end{array}$ & AY116670 \\
\hline РaTBH1 & $\begin{array}{l}\text { CAAGCATCACGTGGTGCAATAC } \\
\text { CATCTCTGATGTGTCGTGTGAAC } \\
\text { CAAGCATCACGTGGTGCAATAC } \\
\text { TGAGTATGCCTTCCGTTGGC }\end{array}$ & $\begin{array}{l}560^{a} \\
494\end{array}$ & EF595743 \\
\hline FMRF amide precursor & $\begin{array}{l}\text { GTCGAGGACATGATTTTGACC } \\
\text { CCAAATCTTATGAAGTTGCTGCCTG } \\
\text { CGGGAGAAAAAGACGAAAGTCTTG } \\
\text { CCCACGTCCCACCCTCAGA }\end{array}$ & $\begin{array}{l}523^{a} \\
452\end{array}$ & AY33345 \\
\hline PaNav1 & $\begin{array}{l}\text { CCTCGGCTTCAAGAAGTAC } \\
\text { CATGATCTGAATCCATCCC } \\
\text { CCTCGGCTTCAAGAAGTAC } \\
\text { CGTGTAGTTCTCAGCAATGC }\end{array}$ & $\begin{array}{l}479^{a} \\
386\end{array}$ & GQ132119 \\
\hline
\end{tabular}

${ }^{a}$ CDNA length obtained in the first multiplex PCR round.

http://www.jme.endocrinology-journals.org DOI: $10.1530 / J M E-12-0202$
(C) 2013 Society for Endocrinology Printed in Great Britain
Published by Bioscientifica Ltd 


\section{TBH assay}

The assay is based on the hydroxylation of tyramine (Lehman et al. 2000a,b) (5 mM ascorbic acid and $0.76 \mathrm{mM}$ purified tyramine). All steps were performed in dark or under dim light. The homogenates were added (final concentration $50 \mu \mathrm{g}$ protein $/ \mathrm{ml})$ in assay buffer $(0.1 \mathrm{M}$ potassium phosphate, $\mathrm{pH} 6.9,1 \mathrm{mg} / \mathrm{ml}$ catalase, $0.1 \mathrm{mM}$ $N$-ethylmaleimide, $0.05 \mathrm{mM} \mathrm{CuSO}, 5 \mathrm{mM}$ disodium fumarate, $5 \mathrm{mM}$ ascorbic acid and $0.76 \mathrm{mM}$ purified tyramine, and $0.007 \mathrm{Ci} / \mathrm{mol}$ purified tyramine) and incubated at room temperature for $30 \mathrm{~min}$ without shaking. The reaction was immediately stopped by thermal shock $\left(5 \mathrm{~min}, 98^{\circ} \mathrm{C}\right)$. The samples were centrifuged at $15000 \boldsymbol{g}$ for $10 \mathrm{~min}$ and the supernatant was collected and used for ELISA analysis. The TBH assays were performed using triplicate samples in at least three independent experiments. Results are presented as picomoles of OA formed per minute per microgram of total protein.

\section{Determination of OA level by ELISA}

All steps were performed in the dark or under dim light. Four buffers (blocking, dilution, washing, and stopping buffer) were prepared before performing the ELISA. Blocking buffer containing 3\% (w/v) BSA in PBS was aliquoted and frozen at $-20{ }^{\circ} \mathrm{C}$ until needed. Dilution buffer containing $0.3 \%$ BSA in PBS was kept at room temperature $\left(22^{\circ} \mathrm{C}\right)$. Washing buffer containing $0.1 \%$ Tween 20 in PBS was frozen at $-20^{\circ} \mathrm{C}$ until needed. Stopping buffer containing $1 \mathrm{M} \mathrm{H}_{2} \mathrm{SO}_{4}$ in distilled water was kept at room temperature. Flat-bottom 96-well ELISA plates (Multisorb, Nunc, Fisher Scientific, Strasbourg, France) were coated with $100 \mu \mathrm{l}$ supernatant $(5 \mu \mathrm{g}$ protein/well) and incubated for $3 \mathrm{~h}$ under gentle shaking at room temperature. After three washes with $150 \mu \mathrm{l} /$ well of washing buffer, the plates were blocked with $100 \mu \mathrm{l} /$ well of blocking buffer overnight at $4{ }^{\circ} \mathrm{C}$. After three washes with $150 \mu \mathrm{l} /$ well of washing buffer, the plates were

\section{Figure 1}

Nucleotide and deduced amino acid sequences of $\mathrm{PaTBH}$. The open reading frame begins at nucleotide 18 (sequence ATG:Met) and closes at nucleotide
1749 (TAA). A putative polyadenylation signal is underlined. The numbers on the right indicate the position of the nucleotides.

Published by Bioscientifica Ltc. 
incubated with $100 \mu \mathrm{l} /$ well of the anti-OA polyclonal antibody (1:1000 in dilution buffer, ab37092; Abcam, Paris, France) and for $1 \mathrm{~h}$ under gentle shaking at room temperature. After three washes with $150 \mu \mathrm{l} /$ well, the plates were incubated with $100 \mu \mathrm{l} /$ well of the peroxidaseconjugated secondary antibody (1:10 000 dilution, A0545; Sigma-Aldrich) for $3 \mathrm{~h}$ under gentle shaking at room temperature. The plates were then washed three times with $150 \mu \mathrm{l}$ washing buffer, and $100 \mu \mathrm{l}$ 3,3,5,5-tetramethylbenzidine (T8665; Sigma-Aldrich) were added to each well. After $20 \mathrm{~min}$ of incubation under shaking at room temperature, the reaction was stopped by addition of $10 \mu \mathrm{l}$ stopping buffer. The absorbance of the developed coloration was measured at $450 \mathrm{~nm}$ using Titertek MultiScan Plus microplate reader. The OA assays were performed using triplicate samples in, at least, three independent experiments. Before the experiments, the cross-reactivity between $\mathrm{OA}$ and tyramine and the sensitivity of the ELISA test were verified.

\section{Statistical analysis}

The sequenced data were analyzed using the BioEdit sequence analysis software. Full-length ORFs were identified using BLAST research in GenBank database (http:// www.ncbi.nlm.nih.gov/blast/Blast.cgi). Then the alignment of amino acids sequences was carried out with Clustal $\mathrm{W}$ as already described (Moignot et al. 2009). The annotation of protein sequences with the location of domains was performed using the NCBI's Conserved Domain Database (Marchler-Bauer et al. 2011) and SignalP 4.0 Server 5 (Petersen et al. 2011). Statistical analysis of ELISA assay data was analyzed using GraphPad Prism software (version 3) (GraphPad Software, La Jolla, USA). Results are given as mean \pm s.E.M. The measured values were analyzed using a ANOVA followed by a Bonferroni post hoc test. Statistical significance was accepted at ${ }^{*} P<0.05,{ }^{* *} P<0.01$, and ${ }^{* *} P<0.001$.

\section{Results}

\section{Cloning of TBH CDNAs in nerve cord of $P$. americana}

RT-PCR and cloning experiments allowed us to constitute a composite full-length cDNA sequence of $1865 \mathrm{bp}$ expressed in the nerve cord tissue of $P$. americana (Fig. 1, GenBank ID: JQ316453). This sequence contains an ORF 1734 bp encoding 577 amino acids residues, flanked by a 17 bp UTR and a 66 bp 3'-UTR. This latter displays a polyA tail and a polyadenylation site ('AATAAA'). Due to its relative high-identity amino acid sequence with $\mathrm{TBH}$ of D. melanogaster (48.8\%, GenBank ID: CAA94391), the protein encoded by this composite cDNA was named PaTBH for TBH of $P$. americana. Afterward, specific primer pairs (Table 1) were designed to amplify the complete ORF by RT-PCR. To minimize error during amplification, a proofreading thermostable DNA polymerase was used for amplification. Nevertheless, we obtained very low cloning efficiencies. Only eight positive clones containing $\mathrm{PaTBH}$ cDNAs were obtained and sequenced twice on both strands. Four different amino acid sequences were deduced from the cloned cDNAs and they were called $\mathrm{PaTBH}_{1-4}$. These four full-length cDNAs differ by seven substitutions at the following positions, $68,269,332,352,355,505$, and 507 (Fig. 2). These amino acid substitutions result from seven nucleotide non-synonymous substitutions (A to $G, G$ to $C$, A to $C, G$ to $C, G$ to $T$, $G$ to $T$, and $A$ $G$ respectively). Two other nucleic synonymous substitutions were observed ( $\mathrm{T}$ to $\mathrm{C}$ and $\mathrm{A}$ to $\mathrm{G}$ ).

BLAST analysis showed that the amino acid sequence of PaTBH isoforms contains three distinct domains: a DOMON domain (from position 25 to 148), a copper type II ascorbate-dependent monooxygenase N-terminal domain (Cu-monox-N, from position 193 to 323), and a copper type II ascorbate-dependent monooxygenase C-terminal domain (Cu-monox-C, from position 338 to 502) (Fig. 3A). Multiple alignments showed that these three domains are conserved in five TBHs of insect (Pediculus humanus, Tribolium castaneum, Apis mellifera, Bombyx mori, and D. melanogaster), representing distinct taxons (Hemiptera, Coleoptera, Hymenoptera, Lepidoptera, and Diptera respectively), available in data bank (Fig. 3B and Table 3). The overall sequence of PaTBH shared the highest identity amino acid sequence with PhTBH (57.9\%), while it shared the lowest identity with DmTBH (46.7\%, Table 1). Interestingly, the most conserved domains in all analyzed TBHs were the Cu-monox$\mathrm{N}$ (51.9-64.7\%) and the Cu-monox-C (63.6-70.9\%) domains (Table 3). In contrast, the DOMON domain of PaTBH shares relatively low amino acid identity rate with all the analyzed ТВH (35-50.4\%). The linker between the DOMON and the $\mathrm{Cu}^{2+}$-monox domains is short and divergent among the analyzed TBHs (data not shown). Two hundred and forty-two sequences with the same domain topology were available in data bank.

\section{Expression pattern of PaTBH in different tissues}

Semiquantitative RT-PCR was carried out to characterize the expression of $P a T B H$ in different cockroach tissues

Published by Bioscientifica Ltd. 


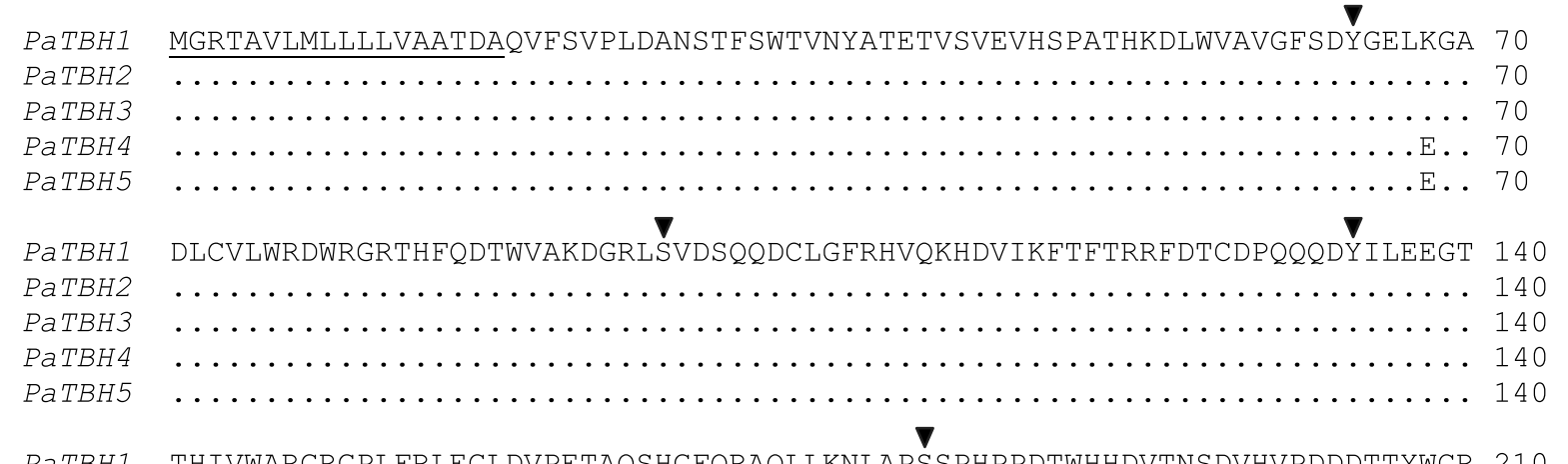

PaTBH1 THIVWARGRGPLFRLEGLDVPETAQSHGFQRAQLLKNLAPSSPHPPDTWHHDVTNSDVHVPDDDTTYWCR 210





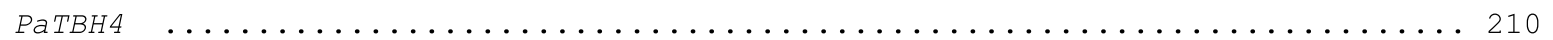



PaTBHI VHRLPAALRTKHHVVQYEATITPGNEALVHHIEVFHCEAPPHEDVPAYEGPCEGPERPRATRVCKRVLAA 280

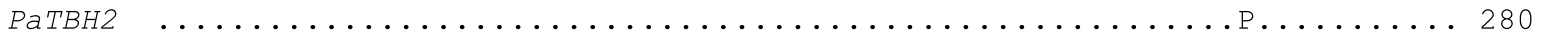

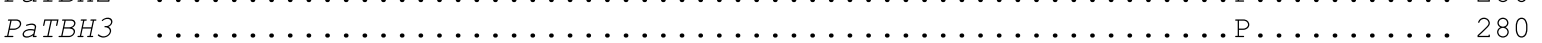

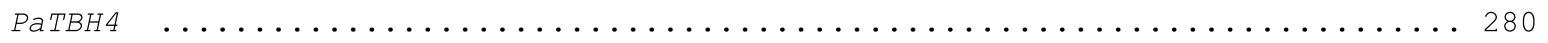

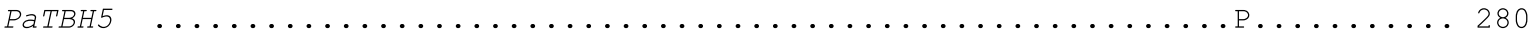

PaTBH1 WAMGALPFSYPEEAGLPIGGLDFNPYVMLEVHYNNPERRADWVDSSGVRLYITPTLRLFDGGVMELGLEY 350



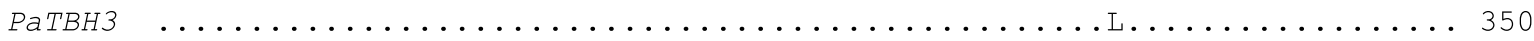

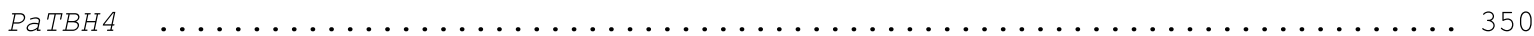

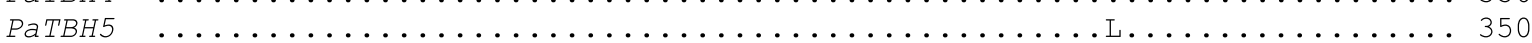

PaTBHI TDKMSIPPKQPAFVLSGYCITECTAVAVPTEGILIFGSQLHTHLTGIRVFTRHIRDGRELPELNRDNHYS 420

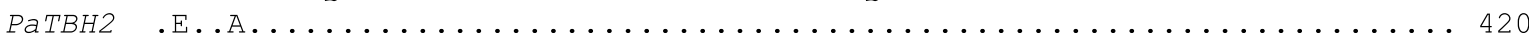

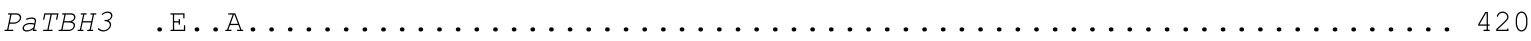

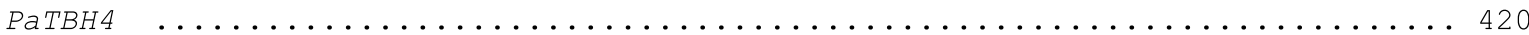

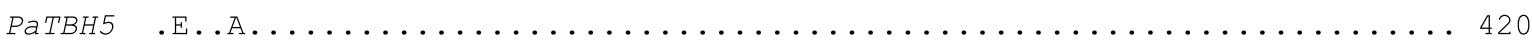

PaTBHI PHFQEIRPLKRQVRLLPGDALITTCWYKTTDRDNITLGGFAISDEMCVNYIHYYPKIDLEVCKSSISSES 490

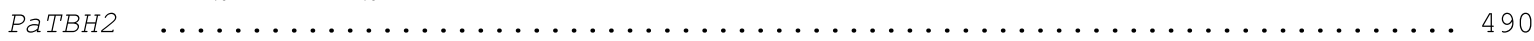

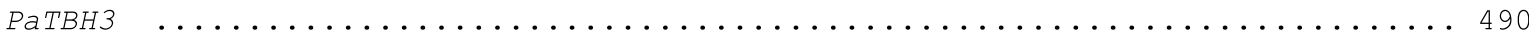

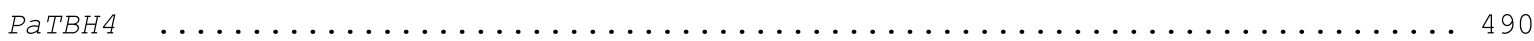

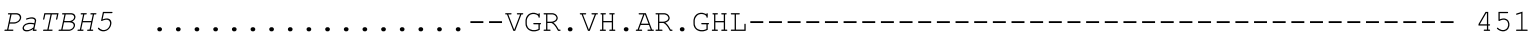

PaTBHI LQSYFRFLHEWEGQSTGPELGISDNYKAVQWSPMRAHVLQELYHETPLSMQCNQSTGERFPGYWENMPIT 560

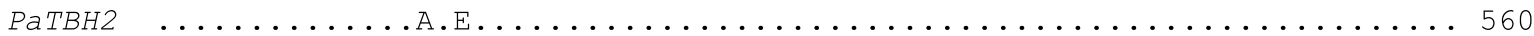





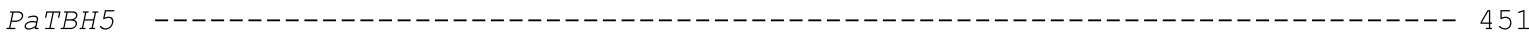

PaTBH1 PVLFPLPPQPRDCSKQH 578

PaTBH2 ......... 578

Ратвн3 .......... 578

PaTBH4 .......... 578

PaTBH5

\section{Figure 2}

Multiple alignment of deduced amino acid sequences of translated PaTBH mRNAs in $P$. americana. Clustal W program was used to align five different amino acid sequences that were deduced from full-length cDNAs cloned in the nerve cord $P$. americana. PaTBH1 corresponds to the composite CDNA Printed in Great Britain
(C) 2013 Society for Endocrinology
(GenBank ID: JQ316453). PaTBH2 to PaTBH5 (GenBank ID: JQ316454 to JQ316458) are four isoforms. PaTBH5 is a truncated form of PaTBH. The peptide signal sequence at position 1-18 is underlined and putative phosphorylation sites are indicated by triangle.

Published by Bioscientifica Ltd 
A

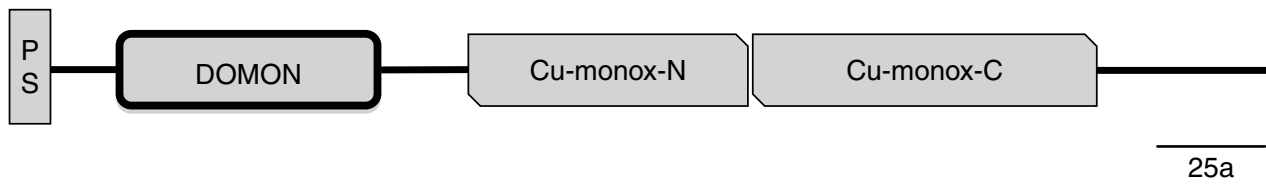

B

DOMON domain

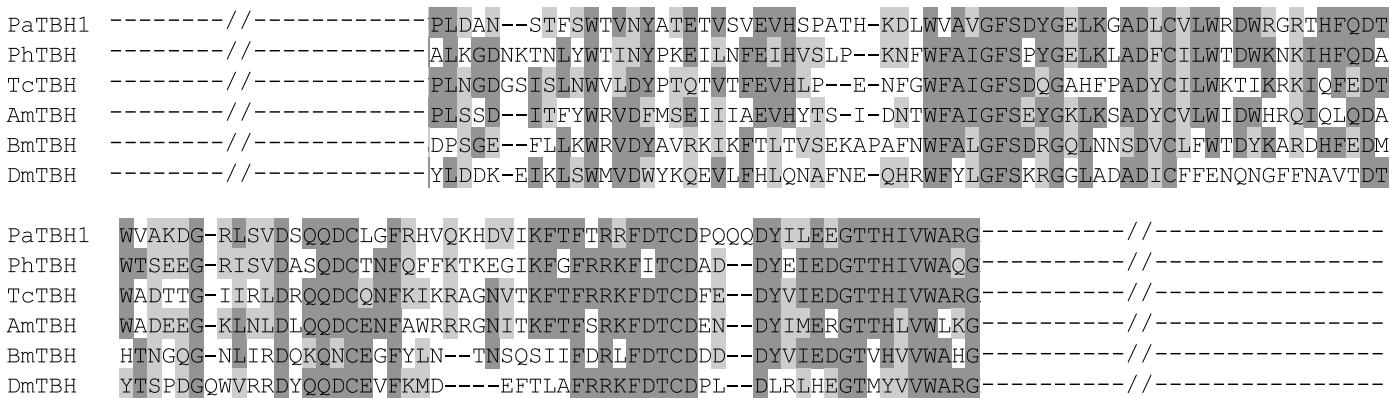

DmTBH

$$
\mathrm{Cu}^{2+}-\text { monox domains }
$$

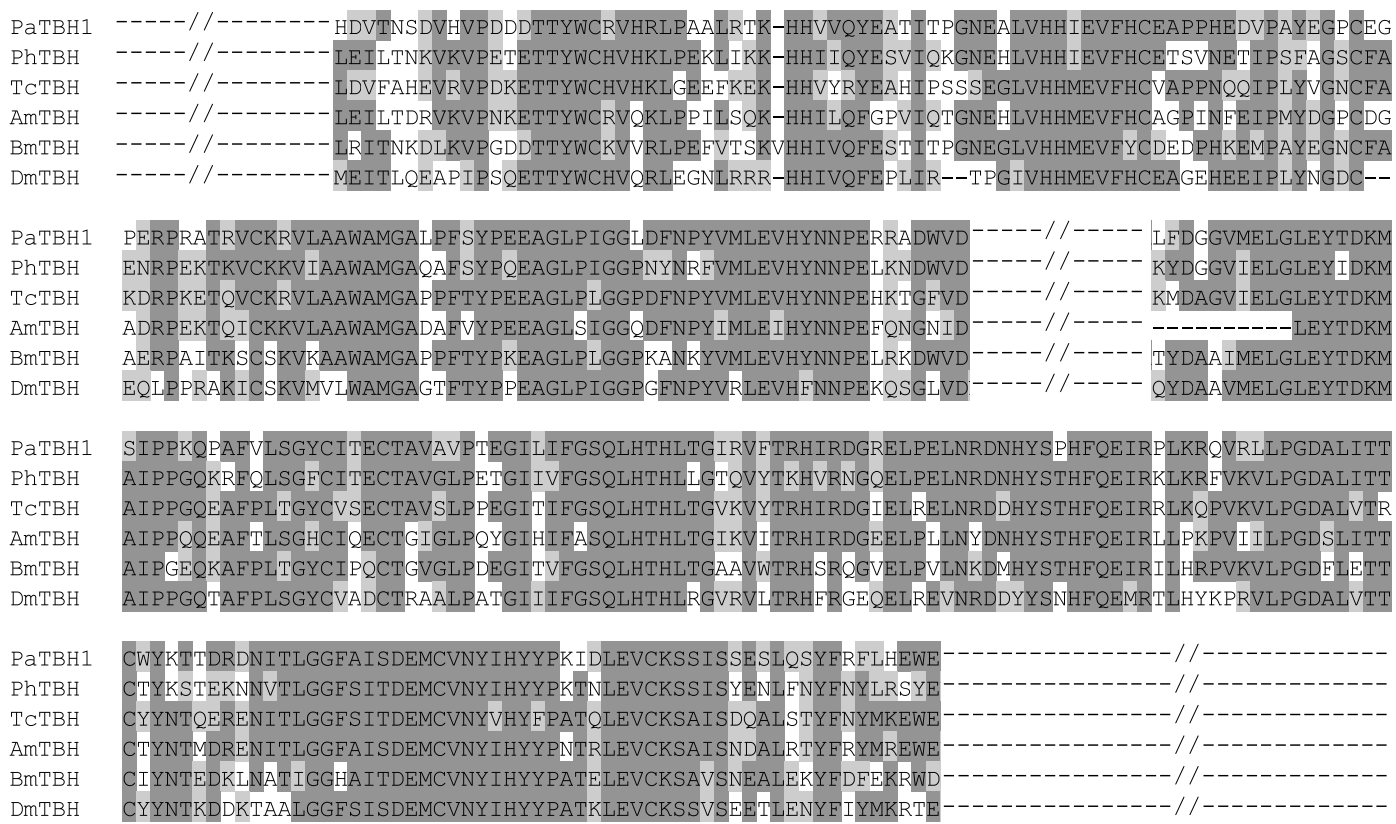

\section{Figure 3}

Clustal W alignment of TBH of $P$. americana and of other insect species. (A) The domain architecture of DBH and TBH. PS, signal peptide, copper type II ascorbate-dependent monooxygenase, $\mathrm{N}$-terminal domain (Cu-monox- $\mathrm{N}$ ) and C-terminal (Cu-monox-C) domain. (B) Clustal W alignment of PaTBH1 (GenBank ID: JQ316453), PhTBH (GenBank ID: XP_002425605), TcTBH

(Fig. 4B, $n=5$ ). Surprisingly, PaTBH was poorly detected in head in comparison to the ventral nerve cord and the ganglia where high expression levels of $\mathrm{PaTBH}$ were observed, as shown in Fig. 4A. PaTBH expression was not detectable in muscle, mushroom-shaped accessory gland, and gut. In addition, $P a T B H$ transcript was also detected in isolated DUM neurons by multiplex single-cell RT-PCR.
(GenBank ID: XP_974169), AmTBH (GenBank ID: NP_001071292), DmTBH (GenBank ID: BAK09201), and MmTBH (GenBank ID: NP_620392). For clarity reasons, only DOMON and $\mathrm{Cu}^{2+}$-monox domains were shown. Identical amino acid residues are highlighted in dark gray and similar ones are in light gray color.

\section{The effects of mechanical stress on TBH activity and OA level}

ELISA assay was assessed to determine TBH activity through the measurement of OA level, as it is a simple, fast, cost-effective, and sensitive method. Several ELISA plates were first tested for their ability to bind nonconjugated OA molecules. The Nunc Multisorb ELISA

Published by Bioscientifica Ltd. 
Table 3 Amino acid sequence identity between TBH of $P$. americana and other insect species

\begin{tabular}{|c|c|c|c|c|c|c|c|c|}
\hline \multirow[b]{3}{*}{ Species } & \multirow[b]{3}{*}{ GenBank ID } & \multirow[b]{2}{*}{ Overall } & \multirow{2}{*}{\multicolumn{2}{|c|}{ DOMON $^{a}$}} & \multicolumn{4}{|c|}{$\mathrm{Cu}^{2+}$-monox domains } \\
\hline & & & & & \multicolumn{2}{|l|}{$\mathrm{N}$-terminal } & \multicolumn{2}{|l|}{ C-terminal } \\
\hline & & Identity (\%) & Position & Identity (\%) & Position & Identity (\%) & Position & Identity (\%) \\
\hline P. americana & JQ316453 & 100 & $25-148$ & 100 & $191-323$ & 100.0 & $338-502$ & 100.0 \\
\hline P. humanus & XP_002425605 & 57.9 & 29-149 & 50.4 & $191-323$ & 59.4 & $338-502$ & 70.9 \\
\hline T. castaneum & XP_974169 & 56.6 & $28-147$ & 47.5 & $190-322$ & 63.2 & $337-501$ & 69.1 \\
\hline A. mellifera & NP_001071292 & 54.1 & $82-202$ & 47.9 & $244-376$ & 57.1 & $376-537$ & 70.2 \\
\hline B. mori & BAK09201 & 51.9 & $38-158$ & 36.7 & 199-332 & 64.7 & $347-511$ & 64.2 \\
\hline D. melanogaster & CAA94391 & 46.7 & $94-212$ & 35.0 & $257-385$ & 51.9 & $400-564$ & 63.6 \\
\hline
\end{tabular}

${ }^{a}$ The conserved dopamine $\beta$-monooxygenase $\mathrm{N}$-terminal domain (Aravind 2001).

plates gave the best results because they have a high affinity with hydrophilic molecules, e.g. OA, due to their polystyrene surface.

First of all, so as to define the optimal conditions of the assay, commercial OA was coated onto this ELISA plate and revealed using a commercial anti-OA antibody that has 400 times more affinity for OA than for tyramine, according to the manufacturer (for other molecules such as noradrenaline and dopamine, the antibody has 10000 times less affinity for them compared with OA). Different quantities of $\mathrm{OA}$ were coated onto the plate in the presence or absence of tyramine. Results did not show any cross-reactivity between tyramine and $\mathrm{OA}$, as observed in Fig. 5.

Then, sensitivity of the assay has been tested by coating on the ELISA plate different concentrations of OA. Results showed that the OA concentration and OD were linear from 2.5 to $50 \mathrm{nmol}$ of $\mathrm{OA}$ coated and then detection reached a plateau from $50 \mathrm{nmol} \mathrm{OA} /$ well (Fig. 6).

Sensitivity of the assay was also assessed by measuring the limit of detection (LOD) and the limit of quantification (LOQ) parameters. LOD is the lowest concentration of analyte that can be detected and reliably distinguished from zero (or the noise level of the system) but not necessarily quantified; the concentration at which a measured value is larger than the uncertainty associated with it. LOD can be expressed in response units $\left(\mathrm{Y}_{\mathrm{LOD}}\right)$ and is taken typically as three times the noise level. Otherwise, it is commonly estimated using the expression (IUPAC 1997): $Y_{\text {LOD }}=Y_{\text {blank }}+3 S_{\text {blank }}$ (where $Y_{\text {blank }}$ and $S_{\text {blank }}$ are the average value of the blank signal and its corresponding s.D. respectively obtained by measuring at least a minimum of 4 independent sample blanks).

LOQ is the lowest concentration of analyte that can be determined quantitatively with an acceptable level of precision (citer IUPAC 1998). The procedure for evaluating LOQs is equivalent to that of LODs, by measuring at least four independent sample blanks: $\mathrm{Y}_{\mathrm{LOQ}}=\mathrm{Y}_{\text {blank }}+10 \mathrm{~S}_{\text {blank }}$.

Concerning our developed ELISA assay, those parameters gave results as follows: $\mathrm{Y}_{\mathrm{LOD}}=0.21433 \mathrm{nmol} / \mathrm{well}$ and $\mathrm{Y}_{\mathrm{LOQ}}=0.71385 \mathrm{nmol} / \mathrm{well}$.

Concerning the inter- and intra-assay variability, the low quantity of protein extracted from the nervous

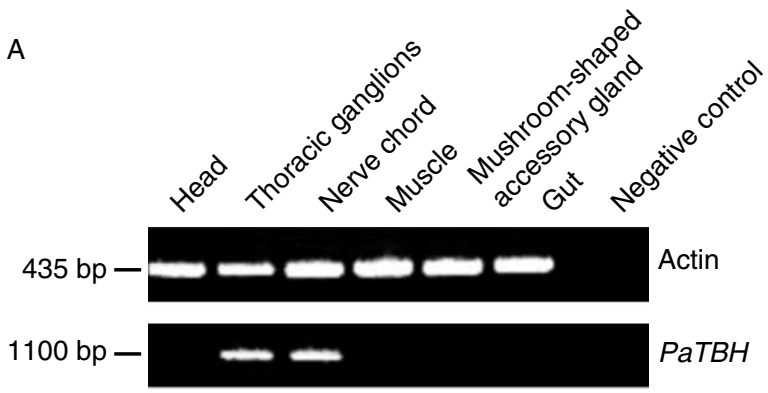

B

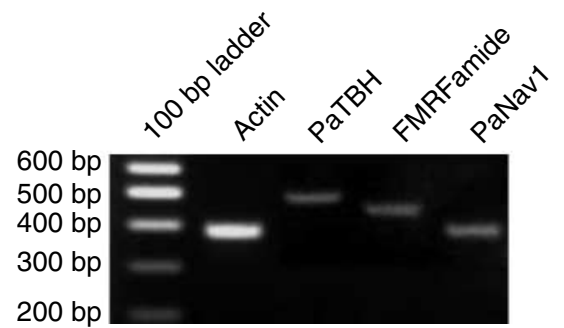

Figure 4

PaTBH transcript expression profiles by RT-PCR. (A) Detection by RT-PCR of $P$ aTBH transcript in various tissues. Equal intensities of actin bands (GenBank ID: AY116670) in each lane warrant the semiquantitative detection of the CDNA originating from each mRNA existed in each tissue. (B) Multiplex single-cell RT-PCR showed the expression of actin (386 bp), PaTBH1 (494 bp), FMRFamide precursor (GenBank ID: AY33345, 452 bp), and PaNav1 (sodium channel, GenBank ID: GQ132119, 386 bp) in DUM neurons.

Published by Bioscientifica Ltd. 


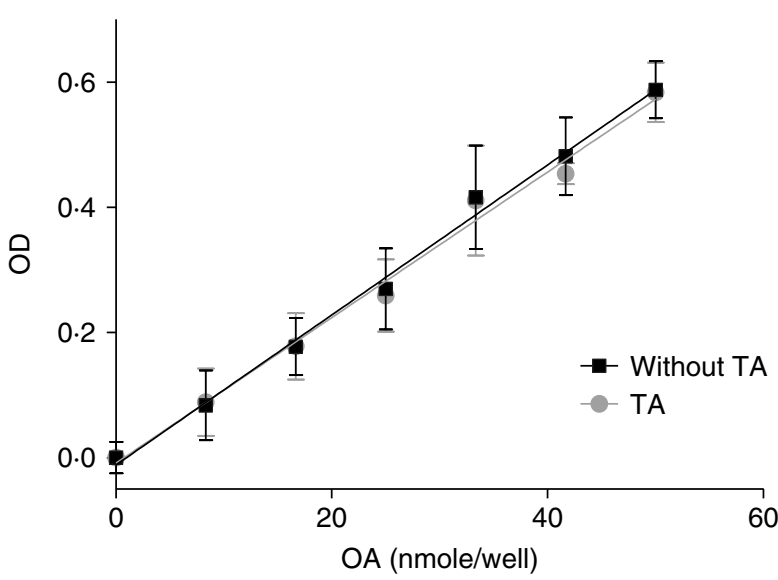

Figure 5

Cross-reactivity evaluation between tyramine and octopamine (OA) for the ELISA test development. Different quantities of OA were coated on the ELISA plate with or without tyramine $(3.8 \mathrm{nmol} /$ well).

cord of cockroach does not allow to test several protein concentrations and many replicates. However, for the assay development, it was verified that the coating of $2 \mu \mathrm{g}$ cockroach protein extract induced twofold increase in OD compared with $1 \mu \mathrm{g}(3.43 \pm 1.36$ vs $1.73 \pm 0.55 \mathrm{nmol} /$ well), which demonstrated the identical binding affinity of the antibody for cockroach OA and for commercial OA.

Afterward, this ELISA test was used on protein extract of cockroaches subjected to mechanical stress for 1 or $24 \mathrm{~h}$. Two analyses were performed: i) direct detection of $\mathrm{OA}$ in protein extract of cockroaches and ii) detection of $\mathrm{OA}$ after incubation of the protein extract with TBH substrate (tyramine), which enables to measure OA production and hence to deduce TBH activity level in stress condition. Concerning the first analysis (direct measurement of OA level in protein extract), results did not show any significant increase in OA level in the nerve cord after 1 or $24 \mathrm{~h}$ of stressful stimulation (Fig. 7).

For the second type of analysis, BTH enzymatic assay was developed, according to the protocol of Lehman et al. $(2000 a, b)$. We observed that the maximal TBH activity in $P$. americana occurred within $30 \mathrm{~min}$ for the enzymatic test and that $2 \mu \mathrm{g}$ total protein extract was the limit detection sensitivity of the assay.

Interestingly, results showed that the activity of TBH, measured by $\mathrm{OA}$ amounts produced at the end of the enzymatic assay, was increased by mechanical stress (Fig. 8). Resulting TBH activity was higher in animals exposed to 1 -h stress $\left(27.97 \pm 7.05\right.$ vs $0.33 \pm 0.07 \mathrm{pmol} \cdot \mu \mathrm{g}^{-1} \cdot \mathrm{min}^{-1} \mathrm{OA}$ in controls) compared with 24 -h stress $(16.30 \pm 5.52$ vs $0.33 \pm 0.07 \mathrm{pmol} \cdot \mu \mathrm{g}^{-1} \cdot \mathrm{min}^{-1} \mathrm{OA}$ in controls).

\section{Discussion}

In this study, we have cloned four full-length cDNA sequences encoding TBH from the nervous system of the cockroach $P$. americana. PaTBH expression pattern analysis in different cockroach tissues showed that $P a T B H$ was highly expressed in the nervous system of $P$. americana. Our data are consistent with a neuronal tissue-specific expression of $P a T B H$ with the fact that OA is only synthesized by octopaminergic neurons.

The deduced amino acid sequences of these cDNAs share high-identity amino acid sequence with TBH of $D$. melanogaster. Interestingly, the four different amino acid sequences obtained, called $\mathrm{PaTBH}_{1-4}$, result from seven nucleotide substitutions in their cDNA sequences. These nucleotide substitutions were certainly due to individual polymorphism, such as single nucleotide polymorphism (SNP). To date, no SNP has been reported yet for TBH of insect. Conversely, several SNPs have been described for $\mathrm{hDBH}$, which is reported to be involved in diseases such as migraine and attention-deficit hyperactivity disorder (Zabetian et al. 2001, Kopeckova et al. 2006, Fernandez et al. 2009). However, the functional consequences of SNP are not well understood. The nucleotide substitutions observed in cDNA might also be the result of A-I and C-I RNA editing. Indeed, RNA editing is a frequent mechanism leading to molecular diversity in the nervous system



Figure 6

Evaluation of the range of sensitivity of the ELISA assay for detection of octopamine (OA). Different quantities of OA were coated on the ELISA test and detected with the polyclonal antibody anti-OA.

Published by Bioscientifica Ltd. 


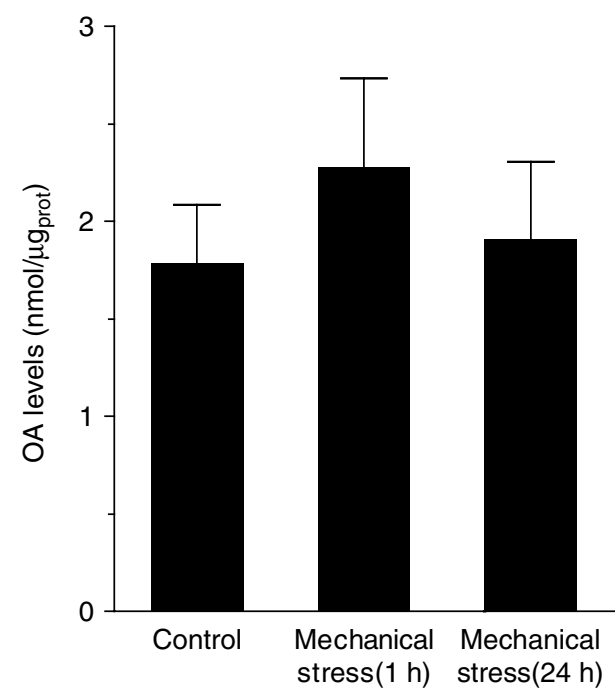

\section{Figure 7}

Effect of mechanical stress on OA level in $P$. americana. OA levels were measured by ELISA in the nerve cord using triplicate samples in at least three independent experiments after 1 and $24 \mathrm{~h}$ of mechanical stress. Data are shown as mean \pm s.E.M. from each group ( $n=16$ per group).

(Jepson \& Reenan 2008). Moreover, a fifth shorter cDNA encoding was also obtained. This latter differs from the other four cDNAs by the lack of a $188 \mathrm{bp}$ fragment that likely results in a splicing event. However, to date, RNA editing and alternative events have not been observed in encoding TBH enzymes. These processes may be involved in the tuning of the enzymatic activity of TBH and consequently may regulate OA level in insect body.

The amino acid sequences of PaTBH isoforms are structurally organized according to the domain architecture of $\mathrm{DBH}$, which contains three highly conserved domains, a DOMON domain, a copper type II ascorbatedependent monooxygenase $\mathrm{N}$-terminal domain, and a copper type II ascorbate-dependent monooxygenase C-terminal domain (Aravind 2001, Kapoor et al. 2011). The DOMON domain was initially described in secreted and membrane proteins in all phyla and was proposed to mediate a range of extracellular adhesive interactions (Aravind 2001). Computational analysis showed that this domain is very diverse and is involved in heme and sugar recognition (Iyer et al. 2007). More recently, structural analysis of $\mathrm{hDBH}$ suggested that the DOMON domain promotes tetramerization of the enzyme, while the Cu-monox-C domain controls dimerization (Kapoor et al. 2011). The $\mathrm{Cu}^{2+}$-monox domain corresponds to the catalytic domain of the protein. This explains the high conservation rate between TBHs and DBHs.
Peptidylglycine $\alpha$-monooxygenases also contain $\mathrm{Cu}^{2+}$ monox domain, but in these latter, the DOMON domains are missing (Aravind 2001).

TBH activity was analyzed using a new ELISA assay in nerve tissue of normal cockroaches as well as mechanical stressed animals. This enzymatic assay protocol was adapted from the one developed by Lehman et al. $(2000 a, b)$ on the moth M. sexta. Incubation of crude nerve cord extract with tyramine results in the formation of OA, which is detectable by ELISA assay. This assay requires catalase (Wallace 1976, Lehman et al. 2000a,b) and is based on the conversion of tyramine to OA by the TBH contained in the tissue protein extract. Previous studies conducted on several animals including cockroach used radioactive HPLC detection technique (Lehman et al. $2000 a, b)$, which is a very precise assay for activity quantification. The ELISA assay used in this study, although less sensitive, presents some significant advantages: it is a fast quantification and low-cost method, and it is suitable for detection of OA levels in various experimental conditions.

So as to get a better understanding concerning TBH activity regulation, cockroaches have been subjected to mechanical stress for 1 or $24 \mathrm{~h}$. Results showed a maximal activity of TBH after $1 \mathrm{~h}$ of stress, whereas OA level was

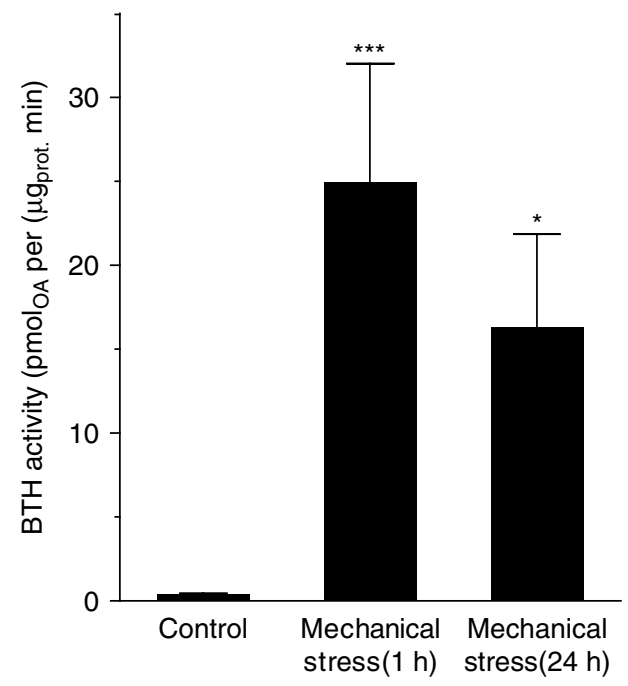

Figure 8

Effect of mechanical stress on TBH activity in $P$. americana. TBH activity was determined by ELISA in the nerve cord of $P$. americana after 1 and $24 \mathrm{~h}$ of mechanical stress. OA was synthesized from tyramine by the TBH. After incubation of tyramine with nervous tissue extract, OA level was measured by ELISA using triplicate samples in at least three independent experiments. Data are shown as mean \pm S.E.M. from each group ( $n=16$ per group). $*, P<0.05 ; * * *, P<0.001$. 
not increased significantly, that did not enable to observe any correlation between OA levels and TBH activity.

Davenport \& Evans (1984) reported in the same insect a peak of OA production after 1 min of mechanical stress that declined during continuous mechanical stimulation, likely resulting from an increase in $\mathrm{TBH}$ activity. As $\mathrm{OA}$ is light sensitive and highly subjected to degradation (Roeder 2005), it seems likely that this molecule was not stable enough for our longer term exposures and that TBH activity was a better indicator of stress induction in the animals than $\mathrm{OA}$.

Davenport \& Evans (1984) made the hypothesis that this upregulation of TBH activity observed in their study might be due to an increase in TBH expression or its activation by phosphorylation (Roeder 2005). So as to verify this hypothesis, semiquantitative RT-PCR was performed for this study on the same samples but did not show any changes in TBH gene expression among the conditions (data not shown).

Some studies have demonstrated that during M. sexta development, induction of TBH activity in the brain and in the ganglia was correlated with an increase in OA levels during metamorphosis. This can be due to i) an increase in TBH levels, ii) an increase in the number of octopaminergic neurons, and/or iii) changes in OA metabolism (OA synthesis, release, uptake, and degradation) (Lehman et al. $2000 a, b)$. Lehman et al. (2006) have demonstrated that elevated $\mathrm{OA}$ levels in forager honey bee brain were correlated with an increase in the expression of gene encoding TBH, thus indicating a link between transcriptional activity, brain OA levels, and the regulation of social behavior in honey bees, which has not been demonstrated in the present work. Several explanations can be proposed to take into account the decrease in OA levels after $24 \mathrm{~h}$ of mechanical stress. First, a negative feedback of TBH activity for OA regulation could occur, as recently demonstrated for catecholamines (Mravec 2011). Secondly, a habituation to mechanical stress can take place, as shown in other invertebrate models (Araki \& Nagayama 2005, Araki et al. 2005).

In summary, we reported i) the identification of a number of SNPs in cDNAs encoding TBH of $P$. americana and ii) the tremendous increase in TBH activity in nerve cord tissue of insects exposed to mechanical stress. We here demonstrated that measurement of TBH activity provided some advantages for stress characterization in insects. Indeed, conversely to $\mathrm{OA}, \mathrm{TBH}$ is not light sensitive, its activity is therefore preserved during sample preparation. OA quantification does not allow us to discriminate $\mathrm{OA}$ synthesis, degradation, or diffusion, while TBH activity measurement specifically indicates OA synthesis. Hence, TBH appears to constitute a more precise element to understand physiological mechanisms activated under stress in insects.

\section{Declaration of interest}

The authors declare that there is no conflict of interest that could be perceived as prejudicing the impartiality of the research reported.

\section{Funding}

This work was supported by the "Conseil Général du Maine et Loire» and the «Collectivités territoriales du Maine et Loire».

\section{Acknowledgements}

The authors thank Prof. Bruno Lapied for his support during this work. They gratefully acknowledge Dr Nathalie Guérineau for critical reading of the manuscript.

\section{References}

Araki M \& Nagayama T 2005 Decrease in excitability of LG following habituation of the crayfish escape reaction. Journal of Comparative Physiology. A, Neuroethology, Sensory, Neural, and Behavioral Physiology 191 481-489. (doi:10.1007/s00359-005-0607-y)

Araki M, Nagayama T \& Sprayberry J 2005 Cyclic AMP mediates serotonininduced synaptic enhancement of lateral giant interneuron of the crayfish. Journal of Neurophysiology 94 2644-2652. (doi:10.1152/ jn.00502.2005)

Aravind L 2001 DOMON: an ancient extracellular domain in dopamine $\beta$-monooxygenase and other proteins. Trends in Biochemical Sciences 26 524-526. (doi:10.1016/S0968-0004(01)01924-7)

Axelrod J \& Saavedra JM 1977 Octopamine. Nature 265 501-504. (doi:10.1038/265501a0)

Chentsova NC, Gruntenko NG, Bogomolova EB, Adonyeva NA, Karpova EK \& Rauschenbach IR 2002 Stress response in Drosophila melanogaster strain inactive with decreased tyramine and octopamine contents. Journal of Comparative Physiology. B, Biochemical, Systemic, and Environmental Physiology 172 643-650. (doi:10.1007/s00360-002-0293-9)

Christensen TA, Lehman HK, Teal PEA, Itagaki H, Tumlinson JH \& Hildebrand JG 1992 Diel changes in the presence and physiological actions of octopamine in the female sex-pheromone glands of heliothine moths. Insect Biochemistry and Molecular Biology 22 841-849. (doi:10.1016/0965-1748(92)90110-Z)

Davenport AP \& Evans PD 1984 Stress-induced changes in the octopamine levels of insect haemolymph. Insect Biochemistry 14 135-143. (doi:10.1016/0020-1790(84)90021-0)

Downer RG 1979 Trehalose production in isolated fat body of the American cockroach, Periplaneta americana. Comparative Biochemistry and Physiology, Part C 62C 31-34. (doi:10.1016/0306-4492(79)90096-0)

Evans PD 1985 Regional differences in responsiveness to octopamine within a locust skeletal muscle. Journal of Physiology 366 331-341.

Farooqui T 2007 Octopamine-mediated neuromodulation of insect senses. Neurochemical Research 32 1511-1529. (doi:10.1007/s11064-007-9344-7)

Fernandez F, Colson N, Quinlan S, MacMillan J, Lea RA \& Griffiths LR 2009 Association between migraine and a functional polymorphism at the dopamine $\beta$-hydroxylase locus. Neurogenetics 10 199-208. (doi:10.1007/s10048-009-0176-2) 
Harris JW, Woodring J \& Harbo JR 1996 Effects of carbon dioxide on levels of biogenic amines in the brains of queenless worker and virgin queen honey bees (Apis mellifera). Journal of Apicultural Research 35 69-78.

Hirashima A \& Eto M 1993 Effect of stress on levels of octopamine, dopamine and serotonin in the American cockroach (Periplaneta americana L.). Comparative Biochemistry and Physiology. Part C, Comparative Pharmacology 105 279-284. (doi:10.1016/07428413(93)90208-3)

Hirashima A, Sukhanova M \& Rauschenbach I 2000 Biogenic amines in Drosophila virilis under stress conditions. Bioscience, Biotechnology, and Biochemistry 64 2625-2630. (doi:10.1271/bbb.64.2625)

IUPAC, International Union of Pure and Applied Chemistry. Compendium of Analytical Nomenclature, Definitive Rules 1987. Oxford, UK: Blackwell Scientific Publications, 1997.

IUPAC, International Union of Pure and Applied Chemistry. Compendium of Analytical Nomenclature, Definitive Rules 1997, 3rd edn. Oxford, UK: Blackwell Science, 1998

Iyer LM, Anantharaman V \& Aravind L 2007 The DOMON domains are involved in heme and sugar recognition. Bioinformatics 23 2660-2664. (doi:10.1093/bioinformatics/btm411)

Jepson JE \& Reenan RA 2008 RNA editing in regulating gene expression in the brain. Biochimica et Biophysica Acta 1779 459-470. (doi:10.1016/j. bbagrm.2007.11.009)

Kapoor A, Shandilya M \& Kundu S 2011 Structural insight of dopamine $\beta$-hydroxylase, a drug target for complex traits, and functional significance of exonic single nucleotide polymorphisms. PLoS ONE 6 e26509. (doi:10.1371/journal.pone.0026509)

Kopeckova M, Paclt I \& Goetz P 2006 Polymorphisms and low plasma activity of dopamine- $\beta$-hydroxylase in ADHD children. Neuro Endocrinology Letters 27 748-754.

Kozanek M, Jurani M \& Somogyiova E 1986 Influence of social stress on monoamine concentration in the central nervous system of the cockroach Nauphoeta cinerea (Blattoidea). Acta Entomologica Bohemoslavica 83171.

Lavialle-Defaix C, Moignot B, Legros C \& Lapied B 2010 How does calciumdependent intracellular regulation of voltage-dependent sodium current increase the sensitivity to the oxadiazine insecticide indoxacarb metabolite decarbomethoxylated JW062 (DCJW) in insect pacemaker neurons? Journal of Pharmacology and Experimental Therapeutics 333 264-272. (doi:10.1124/jpet.109.163519)

Lehman HK, Klukas KA, Gilchrist LS \& Mesce KA 2000a Steroid regulation of octopamine expression during metamorphic development of the moth Manduca sexta. Journal of Comparative Neurology 424 283-296. (doi:10.1002/1096-9861(20000821)424:2<283::AID-CNE7> 3.0.CO;2-Z)

Lehman HK, Murgiuc CM \& Hildebrand JG 2000 $b$ Characterization and developmental regulation of tyramine- $\beta$-hydroxylase in the CNS of the moth, Manduca sexta. Insect Biochemistry and Molecular Biology 30 377-386. (doi:10.1016/S0965-1748(00)00011-4)
Lehman HK, Schulz DJ, Barron AB, Wraight L, Hardison C, Whitney S, Takeuchi H, Paul RK \& Robinson GE 2006 Division of labor in the honey bee (Apis mellifera): the role of tyramine $\beta$-hydroxylase. Journal of Experimental Biology 209 2774-2784. (doi:10.1242/jeb.02296)

Livingstone MS \& Tempel BL 1983 Genetic dissection of monoamine neurotransmitter synthesis in Drosophila. Nature 303 67-70. (doi:10.1038/303067a0)

Marchler-Bauer A, Lu S, Anderson JB, Chitsaz F, Derbyshire MK, DeWeeseScott C, Fong JH, Geer LY, Geer RC, Gonzales NR et al. 2011 CDD: a Conserved Domain Database for the functional annotation of proteins. Nucleic Acids Research 39 D225-D229. (doi:10.1093/nar/gkq1189)

Matthews JR \& Downer RG 1974 Origin of trehalose in stress-induced hyperglycaemia in the American cockroach, Periplaneta americana. Canadian Journal of Zoology 52 1005-1010. (doi:10.1139/z74-134)

Moignot B, Lemaire C, Quinchard S, Lapied B \& Legros C 2009 The discovery of a novel sodium channel in the cockroach Periplaneta americana: evidence for an early duplication of the para-like gene. Insect Biochemistry and Molecular Biology 39 814-823. (doi:10.1016/j.ibmb. 2009.09.006)

Mravec B 2011 Role of catecholamine-induced activation of vagal afferent pathways in regulation of sympathoadrenal system activity: negative feedback loop of stress response. Endocrine Regulations 45 37-41. (doi:10.4149/endo_2011_01_37)

Orchard I \& Loughton BG 1981 Is octopamine a transmitter mediating hormone release in insects? Journal of Neurobiology 12 143-153. (doi:10.1002/neu.480120204)

Petersen TN, Brunak S, von Heijne G \& Nielsen H 2011 SignalP 4.0: discriminating signal peptides from transmembrane regions. Nature Methods 8 785-786. (doi:10.1038/nmeth.1701)

Rauschenbach IY, Sukhanova MZ, Hirashima A, Sutsugu E \& Kuano E 2000 Role of the ecdysteroid system in the regulation of Drosophila reproduction under environmental stress. Doklady Biological Sciences 375 641-643. (doi:10.1023/A:1026610425973)

Roeder T 1999 Octopamine in invertebrates. Progress in Neurobiology 59 533-561. (doi:10.1016/S0301-0082(99)00016-7)

Roeder T 2005 Tyramine and octopamine: ruling behavior and metabolism. Annual Review of Entomology 50 447-477. (doi:10.1146/annurev. ento.50.071803.130404)

Wallace BG 1976 The biosynthesis of octopamine - characterization of lobster tyramine $\beta$-hydroxylase. Journal of Neurochemistry 26 761-770. (doi:10.1111/j.1471-4159.1976.tb04449.x)

Woodring JP, Meier OW \& Rose R 1988 Effect of development, photoperiod, and stress on octopamine levels in the house cricket, Acheta domesticus. Journal of Insect Physiology 34 759-765. (doi:10.1016/ 0022-1910(88)90149-7)

Zabetian CP, Anderson GM, Buxbaum SG, Elston RC, Ichinose H, Nagatsu T, Kim KS, Kim CH, Malison RT, Gelernter J et al. 2001 A quantitative-trait analysis of human plasma-dopamine $\beta$-hydroxylase activity: evidence for a major functional polymorphism at the DBH locus. American Journal of Human Genetics 68 515-522. (doi:10.1086/318198)

Received in final form 26 November 2012

Accepted 29 November 2012

Accepted Preprint published online 29 November 2012 http://www.jme.endocrinology-journals.org DOI: 10.1530/JME-12-0202 (c) 2013 Society for Endocrinology Printed in Great Britain
Published by Bioscientifica Ltd 